\title{
DESCRIPTION OF AND PRELIMINARY DATA FROM A WOMEN'S DUAL DIAGNOSIS COMMUNITY MENTAL HEALTH PROGRAM
}

\author{
LAURA C. HOLDCRAFT and KATHERINE ANNE COMTOIS \\ University of Washington
}

\begin{abstract}
Gender differences in dually diagnosed populations with regard to clinical characteristics and treatment issues suggest that single gender programs for women in particular may be warranted. This article describes an innovative approach taken in the treatment of women with dual diagnoses, a traditionally underserved and unempowered population. The Harborview Mental Health Services Women's Dual Diagnosis Program incorporated empirically based treatments such as cognitive behavioral therapy for dual disorders, dialectical behavior therapy and contingency management into a comprehensive, integrated dual diagnosis program. Preliminary data indicate that this approach has excellent effectiveness in areas such as psychiatric hospitalization, sobriety, productivity, and housing.
\end{abstract}

\section{INTRODUCTION}

Among those served in the community mental health system, women who are dually diagnosed (i.e., have both a severe and persistent mental illness and a substance use disorder) have special treatment needs (Evans \& Sullivan, 1990). Providing these individuals effective treatment is a particular challenge to mental health practitioners. Although dually diagnosed individuals often are discussed as one entity, women and men show very different clinical characteristics (Palacios, Urmann, Newel, \& Hamilton, 1999; Watkins, Shaner, Greer, \& Sullivan, 1999). Several substance abuse treatment studies indicate that women are more frequently diagnosed with depressive disorders than are men (Blume, 1990; Hesselbrock, Meyer, \& Keener, 1985; Lex, 1991). Although infrequently examined among those with major mental illnesses, an outpatient dual diagnosis program found men to have higher rates of schizophrenia and women more likely to be diagnosed with affective disorders (Comtois \& Ries, 1995).

In addition to their higher likelihood of experiencing affective disorders, women are more likely to develop depression before alcoholism and men more likely to develop alcoholism prior to depression (Blume, 1990; Hesselbrock, Meyer, \& Keener, 1985). This tendency has led some researchers to speculate that women are more likely to "self-medicate" their psychiatric symptomatology with substances. There is much debate in the field as to the relationship between substance abuse and mental illnesses (Meyer, 1986); however, the tendency of women to develop depression before alcoholism may very well indicate that self-medication of psychiatric symptomatology is of significant concern for women in particular, and should be addressed in any treatment program. Dual diagnosis treatment protocols 
based on male samples have been directed towards and shown to be effective for individuals with both schizophrenia and substance abuse (Roberts, Shaner, \& Eckman, 1999) and many of those protocols are effective for women. However, when they are applied to women, they may not address the multiple issues that are particularly relevant to women who are dually diagnosed.

Traditionally, those who are dually diagnosed have received treatment for mental illness and substance abuse in separate systems (Ridgely, Goldman, \& Talbott, 1987; Ridgely, Osher, Goldman, \& Talbott, 1987). Outcomes for the dually diagnosed through these systems have been poor, and reviews have recommended integrated treatment (Ridgely et al., 1987; Ridgely, Goldman, \& Willenbring, 1990). Integrated dual diagnosis treatment has several advantages over separate treatments: (a) because treatment is presented by the same clinician or clinicians, patients do not receive conflicting information; (b) patients are not overburdened with two treatment programs; and (c) concepts relevant to the relationship between mental illness and substance abuse can be presented (Minkoff, 1989).

A recent comprehensive review of integrated dual diagnosis treatment programs, primarily in the U.S. (Drake, Mercer-McFadden, Mueser, McHugo, \& Bond, 1998), concluded after an examination of 36 research studies that comprehensive integrated treatment showed the most encouraging results, compared to treatments which solely added dual diagnosis groups, or utilized other methods of integrating treatment. Comprehensive integrated treatments are typically assertive and intensive in nature, and consist of mental health interventions such as medication monitoring, substance abuse treatment, assertive case management, and individual and group therapy (Drake et al., 1998). More recently, they have begun to incorporate techniques for increasing motivation towards goals, and often incorporate principles of motivational interviewing (Carey, 1996; Drake, Bartels, Teague, Noordsy, \& Clark, 1993; Minkoff, 1994), an empirically supported treatment originally developed for treatment of substance use disorders (Miller \& Rollnick, 1991). Comprehensive treatments such as these seem to hold promise. However, because gender analyses were not included in many of the studies in this review, it is unknown whether these techniques are as effective for women as they are for men.

A further issue to be considered is the degree to which empirically supported treatments are utilized to treat dual diagnoses. Perhaps as a result of NIMH initiatives, much progress has been made towards the nation-wide implementation of empirically supported treatments (ESTs). Yet there are many populations, such as women with dual diagnoses, for which an empirically-supported manualized treatment has not been established. Both the report of the Surgeon General (U.S. Public Health Service, 1999) and a recent report from National Institute of Mental Health (1998) promote tailoring interventions to special populations such as women and those with dual diagnoses, populations which are historically underserved in the mental health services system. Additionally, the NIMH report highlights the urgent need for "building bridges among efficacy, effectiveness, practice, and service systems research" (NIMH, 1998). Recent articles have discussed the importance and difficulties of bridging clinical practice with effectiveness research in psychiatry in general (Schoenwald \& Hoagwood, 2001; Wells, 1999) and in the treatment of major mental illnesses in particular (Lehman \& Steinwachs, 1998). Thus, it seems 
to be a complex but essential process to include ESTs in any integrated dual diagnosis program.

In addition to integrating mental health and substance abuse treatment and utilizing ESTs when treating women with dual diagnoses, there are clinical characteristics, societal power and role differentials, and treatment engagement issues specific to women which are essential to address.

\section{Clinical Characteristics}

Personality disorders, such as borderline personality disorder (BPD), often occur alongside substance abuse. Rates of BPD are higher in the substance abusing population than in the general population (Linehan, Schmidt, Dimeff, Craft, Kanter, \& Comtois, 1999). According to the Diagnostic and Statistical Manual of Mental Disorders (1994), the majority (75\%) of those with BPD are women. Often, this combination is so disabling (leading to multiple hospitalizations, loss of relationships, loss of employment and income, etc.) that these individuals experience a "downward drift" in societal status and turn to the public mental health system for assistance and treatment. The high correlation between BPD and gender, as well as the higher prevalence of depression and other affective disorders among women in substance abuse or dual diagnosis treatment, speaks to the importance of treating "emotion dysregulation"-a concept which is defined by difficulties in regulating emotional distress (both related to temperament differences and lack of coping strategies). While the concept of emotional dysregulation was originally coined as a term central to BPD (Linehan, 1993), it is also central to depression, anxiety, and bipolar disorders. If women are more likely to "self-medicate" related negative emotions with alcohol or drugs, effective emotion regulation is crucial to relapse prevention.

\section{Women's Societal Roles and Empowerment}

Individuals who suffer from both substance use disorders and mental illness are doubly burdened and often are stigmatized because of those disorders. Women with both disorders may be at particular risk for stigmatization, ensuing problems with self-esteem, and low confidence in their ability to recover. Women's drinking and, in particular, substance abuse problems traditionally have been more stigmatized than men's (Schmidt et al., 1990), as they conflict with women's traditional gender roles (Holdcraft \& Iacono, 2002; Landrine, Bardwell, \& Dean, 1988; Lemle $\&$ Mishkind, 1989). Furthermore, even though women's roles and status in society have undergone significant change in the U.S. and other countries in the last half of the 20th century (Moen, Erickson, \& Dempster-McClain, 1997; Moen, 1992), women-especially those with substance abuse disorders and mental illness-remain disadvantaged in society.

Additionally, dually diagnosed individuals are at particularly high risk for having been sexually or physically abused (Blankertz, Cnaan, \& Freedman, 1993; Brunette \& Drake, 1997; Ellason, Ross, Sainton, \& Mayron, 1996), traumas in which power or control is taken away. Thus, feelings of powerlessness may frequently contribute to feelings of helplessness and the inability to succeed experienced by dually diagnosed women. Thus, it is crucial for programs designed to treat dually diagnosed women to provide mechanisms and treatment protocols that 
em-power and build confidence and hope through skills training development, motiva-tion enhancement, community support, and education.

\section{Value of Women-Specific Treatment}

One way in which this greater sense of empowerment might be accomplished is by developing a women's program designed for women's treatment issues. Historically, women have underutilized substance abuse treatment programs (Beckman, 1994; Schober \& Annis, 1996; Walitzer \& Connors, 1997); however, data from the early 1990s suggest that higher proportions of women now are being treated for substance abuse (Substance Abuse and Mental Health Services, 1993). There are, nonetheless, many benefits to women-only treatment programs that may be more essential for those who also suffer mental illness. A recent review of women-only compared to mixed-gender programs indicates that, even though there have been few empirical studies to explore this issue, single-gender groups are preferable, primarily because of the male-dominated style and gender composition in mixed-gender programs (Hodgins, El-Guebaly, \& Addington, 1997).

Explanations of the lower treatment participation rates for women include: (a) greater stigmatization of women's problems, (b) treatment protocols designed for men's substance abuse issues, and (c) a lack of understanding of women's substance abuse problems (Beckman 1994; Thom, 1984; Walitzer \& Connors, 1997). Women in co-ed treatment groups often report feeling uncomfortable, being unable to discuss sensitive issues, and having difficulty focusing on their treatment-perhaps due to discrimination or sexual harassment (Powis, Griffiths, Gossop, \& Strang, 1996). In all-women treatment programs, on the other hand, women are better able to: (a) explore gender-specific issues that relate to substance-abuse treatment, (b) create a sense of empowerment by identifying with other women, and (c) feel supported in a women-focused atmosphere.

This paper traces the development of one such program-the Harborview Mental Health Services Women's Dual Diagnosis Program and reports on the data gathered from a preliminary analysis of it.

\section{PROGRAM DEVELOPMENT}

The Harborview Mental Health Services (HMHS) Women's Dual Diagnosis Program was the only public mental health program specifically designed to treat women in the State of Washington. Originally, it was created in response to a study which indicated that there were clear gender differences in diagnoses and group participation levels (Comtois \& Ries, 1995) within HMHS, Seattle's large outpatient community mental health centre. The results of the study-that, overall, women's compliance levels were similar to men's but that women were less likely to attend group treatment, even when it was recommended for them-suggested that there were factors that inhibited co-ed group participation for women. To alleviate some of these obstacles, a Women's Program was created.

\section{Program Structure}

The principles and techniques of the Women's Program were derived from empirically-supported therapeutic models, all of which have been validated with 
other treatment samples, and none of which have been validated with severely and persistently mentally ill and dually diagnosed women. There are four main treatments from which the program principles were derived: (a) Dialectical Behavior Therapy; (b) Community Reinforcement Approach; (c) Contingency Management; and (d) a modification of Cognitive Behavioral Therapy for post-traumatic stress disorder and substance abuse entitled, "Seeking Safety."

Dialectical Behavior Therapy. Dialectical Behavior Therapy (DBT) was originally designed to treat women with borderline personality disorder. It has been shown in a randomized controlled trial to successfully reduce parasuicidal behaviour, psychiatric hospitalizations, and treatment drop-out and to increase global social adjustment (Linehan, Armstrong, Suarez, Allmon, \& Heard, 1991). Fundamental to DBT is the treatment of chronic suicidal behaviours, in part through improving clients' ability to regulate their emotions and tolerate their distress without engaging in impulsive behaviour. In this dual diagnosis program, the treatment of emotion dysregulation is primary, as the patient population consists mostly of women with affective disorders, Axis II disorders, and chronic suicidal behaviour, most of whom have a current or past diagnosis of substance use disorders. The women in this program are diagnosed with: depression $(50 \%)$, bipolar disorder $(25 \%)$ and schizophrenia (15\%). Over half of them were diagnosed with an Axis II personality disorder. DBT provides a conceptual framework to the Women's Program for the treatment of both emotion regulation/psychiatric disorders and substance abuse.

Dialectical Behavior Therapy is a treatment that balances acceptance with change (Linehan, 1993). It encourages a non-judgmental, empathetic view of clients and teaches therapists strategies to build client self-esteem through validation, or enumerating what is valid and reasonable from the clients' perspectives as well as teaching clients to self-validate. Empowerment is accomplished both by encouraging clients to take a more compassionate view of themselves and by behavioural change strategies which assure that clients learn and use new skills to make substantial changes in mental health, sobriety, and basic self-care issues such as housing, employment, and finances. Therapists in the program are trained to teach clients to actively problem-solve. The motto is "teach how to fish rather than give fish." Clients are taught and coached to use DBT skills, which address self-esteem, interpersonal skills, emotion regulation, and crisis survival. These skills help to: (a) increase the client's sense of control, independence, and power; (b) reduce the client's dependence on care providers; and (c) lead to improved confidence, achievement, and self-reliance. Clients, when ready, graduate out of mental health services and obtain primary care treatment. DBT "commitment strategies," which overlap to some extent with motivational interviewing, are one of the primary change strategies used in the program. These strategies help increase motivation to achieve sobriety and long-term goals.

Community Reinforcement Approach. A guiding principle of the program was inspired by the Community Reinforcement Approach (CRA), an approach commonly taken when treating substance abuse but less frequently with mental illness. The Women's Program was designed to promote a life worth living outside of the mental health centre, and CRA helps to foster that outcome by creating communities both inside and outside of the mental health centre that are supportive of mental health, sobriety, and other quality-of-life issues. Clients begin by estab- 
lishing supportive relationships with staff and are encouraged to create supportive relationships with other women in the program as well as individuals in the community at large. Social/recreational activities are sponsored which facilitate these relationships. These activities include a weekly art program, out-of-the-centre social events, and client-co-ordinated celebra-tions of sobriety and other goals.

Building a close community of women within the program who support one another's mental health and sobriety is a high priority. This community-building serves a threefold purpose:

(1) It encourages and teaches women to develop and nurture healthy relationships as a way to promote mental health. In clinical lore, women with severe and persistent mental illness (SPMI) have been thought to have difficulty bonding with other women. In women's theory, on the other hand, it is proposed that women's relationships with other women (as well as with men) are a great source of support and serve as buffers to stress (Jordan, Kaplan, Miller, Stiver, \& Surrey, 1991). This program relies more strongly upon the insights of women's theory.

(2) It enables women to learn alternative effective interpersonal skills. Clinical observations indicate that existing female-to-female relationships are lacking because of inadequate interpersonal skill development-either due to a failure to initiate relationships in the first place or due to faulty or dysfunctional communication and relationship styles (e.g., passive-aggressive, idealization-devaluation). The program helps women to achieve insights into these dysfuntional styles and to learn better ones.

(3) It encouages and assists women to build healthy and supportive communities (friends, family, work environments) outside of the mental health centre. This help is particularly important because relationships formed in the program may foster active coping mechanisms and counter depressive tendencies to isolate and withdraw from relationships and responsibilities in daily life.

Contingency management. Contingency management-that is, explicitly using rewards and aversive contingencies in treatment-is an important aspect of most substance abuse programs and many ESTs for substance abuse (Higgins, 1999). It is a key strategy in DBT (Linehan, 1993) and many CRA programs (Higgins, 1999). The Women's Program focuses on three types of contingency management: (a) highlighting natural contingencies, (b) negative consequences for dysfunctional behaviours, and (c) incentive programs.

Strong emphasis is placed on the women learning to identify and remind themselves of the negative consequences of their impulsive and self-destructive behaviour as well as for their continued avoidance of effective alternatives. Detailed behavioural analyses-in which patients are encouraged to learn the triggering events, dysfunctional thoughts, emotional reactions, and risky behaviours that lead to problem behaviours (drinking, cutting, binges, promiscuity) as well as short and long-term consequences-are conducted. Skillful alternatives are taught and extensive trouble-shooting is conducted to ensure that clients can remember negative consequences and leave or change risky situations.

The Women's Program also makes use of several aversive contingency strategies for continued dysfunctional behaviour. Protective payeeship of substance abusing clients is often required by Social Security or state programs providing 
income. The Women's Program often serves as the payee and less freedom and access to finances is provided when clients are using substances (rent and bills are paid for them, restaurant and grocery store coupons are provided instead of cash, etc.). Requirements for gradually more demanding normative and productive activity were built into the program structure. At first clients were required to do any activity that was incompatible with isolation and symptoms, such as joining community groups, volunteering, starting an exercise program, etc. After gradually increasing the time per week required in this activity from 0 to 20 hours, the requirement switched to attending school or paid work for a certain portion of the 20 hours requirement, again increasing from 0 to 20 hours per week. Failure to maintain these participation or attendance requirements for four consecutive weeks results in discharge from the program. Patients who are discharged are not eligible for readmission for at least three months.

The Women's Program further provides many incentives for using effective behaviours and achieving treatment goals. The women can earn incentive points from things such as attendance, time clean from alcohol and drugs, or followthrough on achieving other goals (such as applying for work, etc.). These points can be exchanged for incentive gifts which have been donated to the clinic (such as movie tickets, compact discs, bath products, etc.). Sobriety birthday parties and certificates of achievement also are provided for milestones in the program. The women in the program are explicitly encouraged to provide support and praise for one another for effective behaviour and to be careful not to attend to or praise dysfunctional behaviours. Randomized urinalyses are conducted as a standard part of the program, and clean urinalyses are often the basis of incentive points. Improved sobriety is reinforced by improved access to funds in the payee programs. Finally, more independent living arrangements become available for women who have achieved long-term sobriety.

As the women become more attuned to the natural consequences of their dysfunctional behaviour, and their sobriety and stability is improved by incentives, natural positive consequences slowly begin to occur (such as income earned on the job, willingness of family to increase contact, and new friends who are supportive of clients and their goals). As these natural consequences take hold, the incentives in the program are no longer needed to maintain success.

Cognitive Behavioral Therapy. The Women's Program originally employed the Substance Abuse Management Model (SAMM) which is in use in other programs at HMHS (Roberts, Shaner, \& Eckman, 1999). SAMM was created for individuals with schizophrenia in the Veteran's Administration system, to target alcohol and drug refusal, improve insight into the behavioural antecedents and consequences of alcohol and drug use, and to teach principles of relapse prevention. The SAMM model emphasizes repetition of key points (e.g., saying "no" to drugs and "yes" to healthy activities), and role-playing interpersonal skills (such as drug refusal, making a request of a case manager, and leaving a high-risk situation). These concepts were important, but did not include information specific to preventing substance abuse in response to emotion dysregulation. Thus, the program was changed to Lisa Najavits' model, Seeking Safety: Cognitive Behavioural Therapy for Post-Traumatic Stress Disorder and Substance Abuse (Najavits, Weiss, Shaw, \& Muenz, 1998), a therapy designed to treat both PTSD and substance abuse within the context of the same program. Given that its principles are readily generalized, 
this therapy was slightly modified for the Women's Program to incorporate other mental illnesses.

The Seeking Safety model is a 25-topic group treatment that emphasizes the concept of "safety"-both with respect to past traumatic experiences and current risky situations often associated with substance abuse among women. It incorporates behavioural principles similar to those used in SAMM along with interpersonal, cognitive, and behavioural topics that are more specific to women with substance abuse disorders (such as principles of healthy relationships, self-nurturing, honesty, compassion, and recovery thinking). It adds a harm-reduction substance-abuse focus to complement the other skills taught in the program. Seeking Safety is an integrated model that treats both mental health and substance abuse simultaneously (whereas SAMM is primarily substance abuse treatment for the mentally ill). There is a "focus on ideals" to help create hope among those who have become hopeless due to substance abuse and one or more traumas. Compared to SAMM, Seeking Safety places a greater emphasis on therapist processes such as: (a) giving clients control when possible, (b) providing validation through focus on client strengths and futures, and (c) identifying the "meaning of substance abuse" and how it relates to emotional problems. While both SAMM and Seeking Safety place a high degree of emphasis on client engagement, Seeking Safety does so through the use of personal stories, weekly quotations which lead to discussion, and allowing clients to choose weekly "commitments" that are flexible according to their current needs.

The program was initially structured as an intensive, outpatient program whose main mode of treatment was group-based. Clients were assigned to beginner and more advanced phases based on their previous involvement with women's programming at HMHS: those with no previous involvement attended up to five groups per week in the beginner phase; those with previous involvement attended up to two groups per week. Clients received coaching and case management, but no individual therapy. This structure seemed to produce good outcomes with respect to sobriety; however, attendance problems and other behaviours that interfered with therapy remained problematic. With group as the main mode of treatment, suicidal behaviours were neither discussed nor treated because of evidence which indicates that discussing suicide in group contexts leads to increased suicidal behaviours (Springer, Lohr, Buchtel, \& Silk, 1996). Therefore, to better target the therapyinterfering and suicidal behaviours, the program structure was changed to reduce therapist time in groups and offer individual therapy.

\section{PROGRAM DESCRIPTION}

As stated above, the SAMM model of teaching skills for reducing substance abuse was changed to the Najavits model. The incentive program and activity/work requirements were added, and the program was explicitly made two years in length in order to improve the contingencies reinforcing active participation and progress. Finally, these contingencies were adjusted to account for difference in the phenomenology of diagnoses by creating the Emotion Dysregulation and Cognitive Disorders tracks (discussed below). 


\section{Inclusion Criteria}

Women were eligible for the program if they had been diagnosed with a major mental illness. Not all women in the program were dually diagnosed; a substance use disorder was not required for admission. Clients must have been 18 years of age or older, a resident of King county, and in need of an intensive two-year program which provides case management.

\section{Treatment Providers}

Although there have been some variations in treatment providers over the duration of the program, the providers have, for the most part, been women. The decision that most clinicians would be female was based on the rationale that an allwomen atmosphere would engender a sense of safety and empowerment for women. The inclusion of a male staff member was observed to be important in order to provide a positive male figure and give women practice interacting positively and effectively with men. Program staff generally has consisted of: (a) one female psychologist, (b) one female master's level social worker, (c) one advanced psychiatry resident (always female), (d) one to two female cause aids, and (e) one male psychiatrist who performed individual and group therapy in addition to medication management.

\section{Program Structure}

There were two tracks to the Women's Program. Clients were enrolled in either the Emotion Dysregulation track or the Cognitive Disorders track. Clients whose primary mental illnesses were affective disorders, anxiety disorders, or personality disorders were considered to be in the Emotion Dysregulation track. Those with schizophrenia, developmental disabilities, or whose psychiatric disorder interfered significantly with the learning process were in the Cognitive Disorders track.

The Emotion Dysregulation track was a two-year program with a one-year beginner phase and a one-year advanced phase. In the beginner phase, women attended three groups per week, including a DBT skills training group, a CBT skills group which used Najavits' material and DBT principles to focus on substance abuse, and a community support group. Both skills groups were didactic in nature; they focused on teaching adaptive coping skills and generalizing these skills to clients' living environments. The community support group afforded an opportunity to practice newly learned interpersonal skills with other women in the program and was a forum to report progress on goals and engage in problem solving. Individual dialectical behavioural therapy was provided on a weekly basis and each client had a "skills coach" who reviewed homework assignments from the skills groups with the client and could provide "in vivo" coaching on practical skills (i.e., applying for school or work, managing finances, etc.). Clients had an activity requirement to ensure that their environment was structured and to increase empowerment through a sense of accomplishment. Clients also were provided with resources, skills training, and support to enter the work force or school and, by the time they graduated from the program, they were spending 20 hours per week in such activities. In the advanced phase, the programs were similar, but clients attended an advanced level DBT skills group that emphasized active problem-solving strategies. 
The Cognitive Disorders track was a time-unlimited program designed to begin with the two-year program described above and continue with an aftercare program providing individual therapy and a DBT skills group. The program was adapted in a few ways which better suit clients with learning difficulties. Shorter individual therapy was provided (30 minutes/week) over a longer course of time (into continuing care). Clients attended a separate DBT skills group which moved at a slower pace and did not have a pre-determined timeline for the activity requirement. The beginner and advanced years of this track were very similar.

Clients with severe therapy-interfering behaviour or uncontrolled suicidal crisis behaviour were treated for a short time in the crisis stabilization phase of the program and were quickly moved into the beginner phase when these targeted behaviours were stabilized. They could, of course, be routed back to the crisis stabilization phase if the need arose.

The program was holistic in the sense that: (a) it provided each client with a case manager, medication management, a payeeship if necessary, and access to all centre resources (including specialists in housing, finances, employment, and nutrition); and (b) its goals attended to most aspects of a client's quality of life, including not only mental health and sobriety but also finances, medication, housing, nutrition, employment or school involvement, and physical health examinations.

\section{PROGRAM EVALUATION}

The HMHS Women's Dual Diagnosis Program was analysed during a pivotal period of time-that is, while a structured curriculum was in place, but while it was still early enough to make adjustments to that curriculum based on the empirical and clinical evaluation of its efficacy. This evaluation was critical in that it: (a) allowed for modification of the existing treatment regime, (b) supported the use of the program as a model for women's dual diagnosis treatment, and (c) provided a basis for beginning the work of creating a treatment manual that will allow other medical health agencies to replicate this model.

The program evaluation consisted of an assessment battery given at intake and at 6-month, 1-year, 18-month and 2-year follow-up assessments. The data presented here represent a preliminary analysis of selected outcome variables for individuals who had completed at least one year of the treatment program. These data include both clients who entered during the previous program structure and those who entered in the program structure described here.

\section{Participants}

Twenty women meeting program criteria and who were enrolled in the program for at least one year ${ }^{1}$ were assessed at intake and at a follow-up assessment approximately one year after entering the program. Demographics are shown in Table 1 . Most women in the program were Caucasian (80 \%), single (75\%), heterosexual $(80 \%)$, and receiving income from social security disability programs $(80 \%)$. Seventy percent were living independently; $30 \%$ were living in residential settings or were homeless when they entered the program. Less than half worked for pay in some capacity, but the majority either worked, volunteered, or were enrolled in school when they were most productive-in the first year of the program. 
A WOMAN'S DUAL DIAGNOSIS COMMUNITY MENTAL HEALTH PROGRAM

TABLE 1

Demographic Characteristics of Clients in the HMHS Women's Dual Diagnosis Program $(\mathrm{N}=\mathbf{2 0})$

\begin{tabular}{lc}
\hline Age in years & $39.3 ! 10.0$ \\
\hline Ethnicity & 80 \\
Caucasian & 15 \\
African American & 05 \\
Asian American & \\
\hline Marital status & 75 \\
Single & 05 \\
Married & 20 \\
Divorced & \\
\hline Sexual orientation & 80 \\
Heterosexual & 15 \\
Lesbian/gay & 05 \\
Unknown & \\
\hline Housing type at intake & 70 \\
Independent & 15 \\
Residential & 15 \\
Homeless & \\
\end{tabular}

Best work status in first year

$\begin{array}{ll}\text { Full time } & 00\end{array}$

Part time $\quad 40$

$\begin{array}{ll}\text { Student } & 10\end{array}$

Volunteer $\quad 35$

$\begin{array}{ll}\text { No structured activity } & 15\end{array}$

Tier funding level

$\begin{array}{ll}\text { Highest (3B) } & 65\end{array}$

Second highest (3A) 30

$\begin{array}{ll}\text { None } & 05\end{array}$

Income source at intake

General unemployment $\quad 15$

$\begin{array}{lr}\text { SSI or SSDI } & 80\end{array}$

Private disability 05

Average monthly income $\$ 606.8 ! 233.6$

Protective payeeship at HMHS 45

Note: Figures reported are precentages with the exception of age and income which are reported in means and standard deviations.

In King County, the level of funding available to clients is inversely associated with functioning scores on the DSM-IV Global Assessment of Functioning (GAF) scale (DSM-IV, 1993). The women in our program had lower GAF scores and, ac- 
cordingly, were funded at higher levels of service: $65 \%$ were funded at the highest level and $30 \%$ were at the second-highest level. These funding levels are essential to the functioning of the program in that they allow for staff to carry a lower caseload, and for a higher number of clinical staff hours to be devoted to each program member. The average income from social security or other government or private disability programs was $\$ 607 /$ month; approximately half received payeeship services through HMHS (at no cost).

Table 2 shows the primary DSM-IV psychiatric diagnoses of record for the women involved in the assessment (DSM-IV, 1993). Clinical diagnoses were determined by the attending psychiatrist who assigned primary and concommittant diagnoses. Major depressive disorder was the most common primary diagnosis, affecting half of the women, and a significant minority (30\%) of those women also experienced psychotic features in association with depression. Twenty-five percent of the women in the program had a primary bipolar I or II disorder, and $15 \%$ were diagnosed with schizophrenia or schizoaffective disorder. Borderline personality disorder was present in $55 \%$ of the women in the program. Three-quarters of the women finishing one year of the program had a current or past substance use disorder (SUD), the most common primary SUD being an alcohol use disorder and the second most common being polysubstance dependence (frequently including alcohol, marijuana, or prescription pain or antianxiety medications).

\section{TABLE 2}

Psychiatric and Substance Use Disorders of Clients in the HMHS Women's Dual Diagnosis Program $(\mathrm{N}=20)$

\begin{tabular}{ll}
\hline Psychiatric or Substance Use Disorders & Percentage \\
\hline Primary psychiatric disorder & 15 \\
Schizophrenia/schizoaffective disorder & 15 \\
MDD with psychotic features & 35 \\
MDD without psychotic features & 25 \\
Bipolar I or II disorder & 05 \\
Anxiety disorder & 05 \\
Borderline personality disorder & 50 \\
\hline Borderline personality disorder present & \\
\hline Primary substance use disorder & 35 \\
Alcohol use disorder & 25 \\
Polysubstance dependence & 10 \\
Cocaine use disorder & 05 \\
Marijuana use disorder & 25 \\
No substance use disorder & 20 \\
\hline Cognitive or physical disability present & \\
\hline
\end{tabular}




\section{Measures}

In the anlaysis, the outcome variables which were assessed included: (a) psychiatric hospitalizations, (b) clinician rating of psychiatric symptoms and global functioning, (c) length of sobriety, (d) client ratings of quality of life, (e) improvements in productivity, and (f) improvements in housing. Hospitalization records were obtained through computerized databases and confirmed with clinicians. Length of sobriety and improvements in productivity and housing (at intake and at approximately one-year follow-up) were reported by each client's clinician. If improvements in housing or productivity were underway but not finalized (e.g., secured housing but not yet moved) this was rated as an improvement. Clinicians rated psychiatric symptoms, treatment compliance, and global functioning on the 4D Case Manager Rating Scale (Comtois \& Ries, 1994). Lehman's Quality of Life interview was given to assess clients' satisfaction with the quality of their lives (Lehman, 1988).

\section{Ethical Issues}

Research at HMHS generally is conducted when it is of direct benefit to client treatment. This research project was reviewed and approved by university, county, and HMHS institutional review boards. Informed consent was obtained in the general clinical services consent process when clients enrolled in HMHS services. Clients in the Women's Program were informed about the purpose and voluntary nature of the program evaluation research assessments. Clients did not receive any monetary compensation for their participation. Data were kept confidential in a locked file cabinet and through the use of study identification numbers. For those who chose to complete the assessments, feedback was available. A packet summarizing clients' responses and scores is under development and clients will be provided with a comparison of their answers at intake and the follow-up assessments. The authors were involved in the administration and provision of services provided to the clients through the treatment program and were paid a salary by the University of Washington, which is affiliated with HMHS. American Psychological Association (2002) ethical guidelines were followed in the conduct of this research.

\section{Results}

The average number of psychiatric hospitalizations (see Figure 1) dropped from 1.6 in the year prior to entering treatment to 0.4 in the first year of treatment, a significant difference $(t(19)=2.4, p<.05)$. The average length of sobriety significantly increased from 15.4 months at intake to 21.3 months at a one-year follow-up $(t(14)=-3.0, p<.05)$, see Figure 2 .

This analysis included individuals who had a sustained period of sobriety before entering the program. However, when this analysis was repeated selecting individuals with less than one year of sobriety before entering the program (see Figure 2), results remained significant with approximately a 5-month increase in sobriety, despite a smaller sample and corresponding loss of power $(t(9)=-2.7$, $p<.05)$.

Housing improvements (see Figure 3), wherein the participant became independent or moved into more permanent housing, were made in $35 \%$ of the sample $\left(X^{2}(1 \mathrm{df}, N=20)=9.1, p<.05\right)$. 


\section{FIGURE 1}

Average Number of Psychiatric Hospitalizations among 20 Women in a Dual Diagnosis Program in the Year Prior to and First Year of Treatment

Figure 1

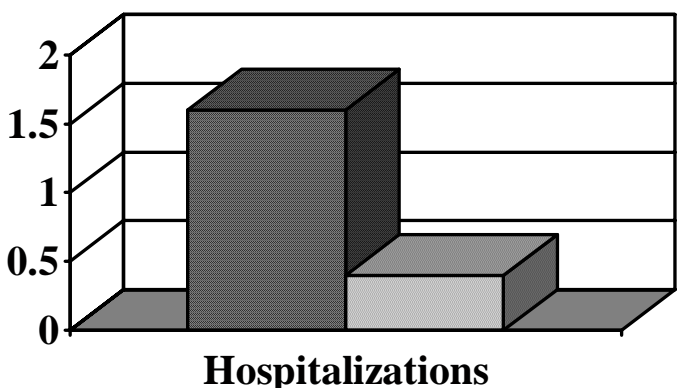

$\square$ Intake

$\square 1$ Year FU

FIGURE 2

Average Months of Sobriety at Intake and at One Year into Dual Diagnosis Treatment

Figure 2

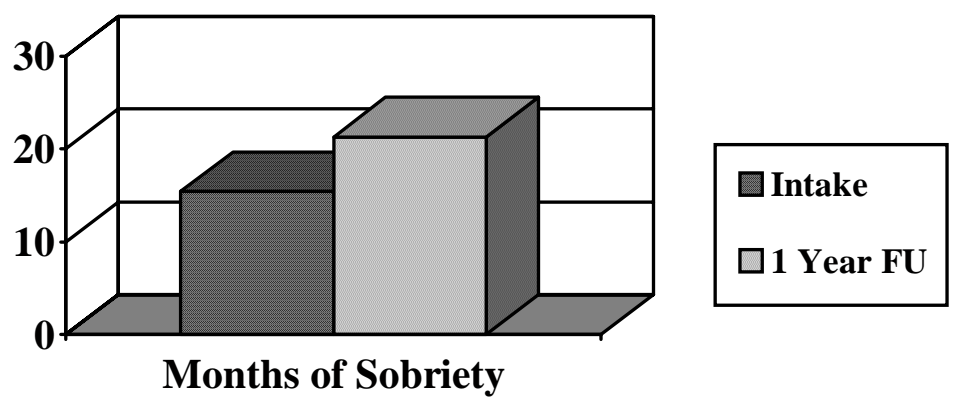

Productivity improvements (See Figure 4), defined as beginning volunteering or working for pay, or increasing volunteer or work hours, were present in $55 \%$ of the sample $\left(X^{2}(1 \mathrm{df}, N=20)=10.3, p=<.01\right)$.

Clients' rating of satisfaction with the quality of their lives at a 1 year followup showed a trend toward improvement, but was not significant $(t(12)=-2.2, p$ $<.10)$. 
FIGURE 3

Changes in Housing Status (Worse, Same, Better) of Dually Diagnosed Women in Treatment

Figure 3
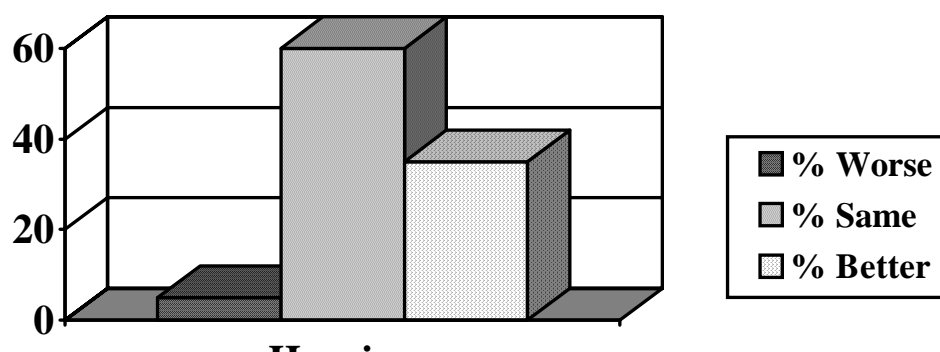

Housing

FIGURE 4

Changes in Productivity (Worse, Same, Better) of Dually Diagnosed

Women in Treatment

Figure 4

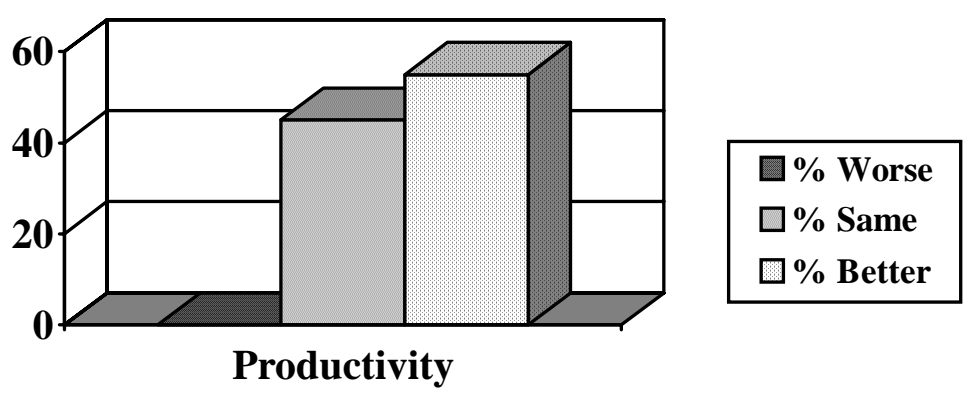

Clinician's ratings indicated significant improvement in psychiatric condition by more than one point on a 7 point scale $(t(10)=4.2, p<.01)$, and a trend level of improvement on global functioning $(t(10)=2.2, p<.10)$.

The results indicate that women served by this innovative integrative dual diagnosis program had significant improvements with regard to substance abuse recovery, productivity, housing arrangements, and psychiatric symptomatology. Overall, quality of life was improved at a trend level of significance. The design of the Women's Program as a gender-specific, behaviourally and educationally-based, 
community support system, which incorporates both substance abuse and mental health treatment, appears to be effective at a preliminary evaluation.

\section{CONCLUSIONS}

The HMHS Women's Dual Diagnosis Program has been effective because it addresses the issues which are often left unaddressed in many substance abuse programs: (a) the integrated mental health and substance abuse treatment provides a comprehensive, skills-based approach to decreasing emotion dysregulation and preventing use of alcohol or drugs in response to it; (b) the women-focused nature of the program allows for greater ease of discussing alcohol or drug-related issues that may affect women differently than men; and (c) in the individual therapy component of the program, therapists help clients identify factors which trigger relapses or other dysfunctional ways of coping with emotional pain and create alternative, healthy solutions.

There are several potential explanations for the non-significant change in ratings of quality of life. Because of the small sample size, it is possible that women perceived their lives to have improved, and that this improvement was clinically but not statistically significant. Alternatively, this finding could reflect a truly nonsignificant difference. Although women sustained improvements with respect to sobriety, mental health, psychiatric hospitalizations, housing, and productivity, almost all remained publicly funded, in subsidized housing, and in the mental health system. The changes necessary to impact client perception of quality of life may not be affected in the first year of treatment.

Limitations of this evaluation include its pre-post nature, which is quasiexperimental in design. This approach suggests that improvements are due to the intervention described; however, a randomized control design or comparison to a matched control sample is needed to rule out the possibility that such changes are not occurring naturally over time. Another limitation that is a function of the first and foremost clinical nature of the program is the fact that clients entered the program when different structures were used. In the future, when a larger number of clients have graduated the program, comparison of different program structures will be made.

Despite the inevitable limitations of clinical research with a program early in development, positive outcomes were obtained. These outcomes are encouraging given the challenging nature of treating those with dual diagnoses and the many obstacles often encountered in providing effective treatment in public mental health agencies. These agencies have many challenges with regard to balancing both quality and quantity of services, such as recent increases in caseloads and the escalating paperwork demands of managed care. With amplified demands on case managers and restrictions on funding for mental health services, the task of improving services is daunting. However, the needs of this population continue to exist and grow - and, without effective treatment programming, the needs of these individuals will be underserved. Therefore, this preliminary success in bringing clinically effective outpatient services to women with both severe and persistent mental illness and substance abuse is both essential and encouraging. 


\section{A WOMAN'S DUAL DIAGNOSIS COMMUNITY MENTAL HEALTH PROGRAM}

\section{NOTE}

1. One participant who dropped below the attendance requirement approximately one month before the one-year point but later rejoined the program was included in these analyses.

\section{RÉSUMÉ}

Les différences attribuées au sexe des individus affectés d'un double diagnostique, en ce qui a trait aux caractéristiques cliniques et au traitement, suggèrent que l'existence de programmes réservés aux femmes pourrait être justifiée. L'article décrit une approche innovatrice adoptée pour le traitement de femmes ayant fait l'objet d'un double diagnostique, une clientèle typiquement mal desservie et sans recours. Le "Women's Dual Diagnosis Program », élaboré par Harborview Mental Health Services, propose un programme complet et intégré destiné aux femmes avec double diagnostique, qui combine des traitements d'inspiration empirique tels que la thérapie béhavioriste cognitive pour double diagnostique, la thérapie béhavioriste dialectique et la gestion des éventualités. Les résultats préliminaires indiquent que cette approche démontre une excellente efficacité, notamment en termes de paramètres comme l'hospitalisation psychiatrique, la sobriété, la productivité et le logement.

\section{REFERENCES}

American Psychological Association. (2002). Ethical principles of psychologists and code of conduct. Washington, DC: Author. Available: http://www.apa.org/ethics.

American Psychiatric Association. (1994). Diagnostic and statistical manual of mental disorders (4th edition). Washington, DC: Author.

Beckman, L.J. (1994). Treatment needs of women with alcohol problems. Health and Research World, 18, 206-211.

Blankertz, L.E., Cnaan, R.A., \& Freedman, E. (1993). Childhood risk factors in dually diagnosed homeless adults. Social Work, 38, 587-596.

Blume, S.B. (1990). Chemical dependency in women: Important issues. American Journal of Alcohol Abuse, (16) 297-307.

Brunette, M.F., \& Drake, R.E. (1997). Gender differences in patients with schizophrenia and substance abuse. Comprehensive Psychiatry, 38, 108-116.

Carey, K.B. (1996). Substance use reduction in the context of outpatient psychiatric treatment: A collaborative, motivational, harm-reduction approach. Community Mental Health Journal, 32, 291-306.

Comtois, K.A., \& Ries, R. (1994). Case manager ratings of dually diagnosed outpatients. Hospital and Community Psychiatry, 45, 568-573.

Comtois, K.A., \& Ries, R. (1995). Sex differences in dually diagnosed severely mentally ill clients in dual diagnosis outpatient treatment. American Journal of Addictions, 4, 245-253.

Drake, R.E., Bartels, S.B., Teague, G.B., Noordsy, D.L., \& Clark, R.E. (1993). Treatment of substance use disorders in severely mentally ill patients. Journal of Nervous and Mental Disease, 181, 606-611.

Drake, R.E., Mercer-McFadden, C., Mueser, K.T., McHugo, G.J., \& Bond, G.R. (1998). Review of integrated mental health and substance abuse treatment for patients with dual disorders. Schizophrenia Bulletin, 24, 589-608.

Ellason, J.W., Ross, C.A., Sainton, K., \& Mayron, L.W. (1996). Axis I and II comorbidity and childhood trauma in chemical dependency. Bulletin of the Menninger Clinic, 60, 3951. 
Evans, K., \& Sullivan, M.J. (1990). Dual diagnosis: Counseling the mentally ill substance abuser. New York: Guilford.

Hesselbrock, M.N., Meyer, R.E., \& Keener, J.J. (1985). Psychopathology in hospitalized alcoholics. Archives of General Psychiatry, 42, 1050-1055.

Higgins, S.T. (1999). Potential contributions of the community reinforcement approach and contingency management to broadening the base of substance abuse treatment. In D.M. Donovan (Ed.), Changing addictive behavior: Bridging clinical and public health strategies (pp. 283-306). New York: Guilford.

Hodgins, D.C., El-Guebaly, N., \& Addington, J. (1997). Treatment of substance abusers: Single or mixed gender programs? Addiction 92, 802-812.

Holdcraft, L.C. \& Iacono, W.G. (2002). Cohort effects on gender differences in alcohol dependence. Addiction, 97, 1025-1036.

Jordan, J., Kaplan, A., Miller, J.B., Stiver, I., \& Surrey, J. (1991). Women's growth in connection. New York: Guilford.

Landrine, H., Bardwell, S., \& Dean, T. (1988). Gender expectations for alcohol use: A study of the significance of the masculine role. Sex Roles, 19, 703-712.

Lehman, A.F. (1988). A quality of life interview for the mentally ill. Evaluation and Program Planning, 11, 51-62.

Lehman, A.F., \& Steinwachs, D.M. (1998). Translating research into practice: The Schizophrenia Patient Outcomes Research Team (PORT) treatment recommendations. Schizophrenia Bulletin, 24(1), 1-10.

Lemle, R., \& Mishkind, M.E. (1989). Alcohol and masculinity. Journal of Substance Abuse Treatment, 6, 213-222.

Lex, B.W. (1991). Some gender differences in alcohol and polysubstance users. Health Psychology, 10, 121-132.

Linehan, M.M. (1993). Cognitive behavioral treatment of borderline personality disorder. New York: Guilford.

Linehan, M.M., Armstrong, H.E., Suarez, A., Allmon, D., \& Heard, H.L. (1991). Cognitive-behavioral treatment for chronically parasuicidal borderline patients. Archives of General Psychiatry, 48, 1060-1064.

Linehan, M.M., Schmidt, H., Dimeff, L.A., Kanter, J.W., Craft, J.C., \& Comtois, K.A. (1999). Dialectical behavior therapy for patients with borderline personality disorder and drug dependence. American Journal on Addictions, 8, 279-292.

Meyer, R.E. (1986). How to understand the relationship between psychopathology and addictive disorders: Another example of the chicken and the egg. In R.E. Meyer (Ed.), Psychopathology and addictive disorders (pp. 3-16). New York: Guilford.

Miller, W.R., \& Rollnick, S. (1991). Motivational interviewing: Preparing people to change addictive behavior. New York: Guilford.

Minkoff, K. (1989). An integrated treatment model for dual diagnosis of psychosis and addiction. Hospital and Community Psychiatry, 40, 1031-1036.

Minkoff, K. (1994). Treating the dually diagnosed in psychiatric settings. In N.S. Miller (Ed.), Treating coexisting psychiatric and addictive disorders: A practical guide (pp. 5368). Center City, MN: Hazelden.

Moen, P. (1992). Women's two roles: A contemporary dilemma. New York: Auburn.

Moen, P., Erickson, M.A., \& Dempster-McClain, D. (1997). Their mother's daughters? The intergenerational transmission of gender attitudes in a world of changing roles. Journal of Marriage and the Family, 59, 281-293.

Najavits, L.M., Weiss, R.D., Shaw, S.R., \& Muenz, L.R. (1998) "Seeking Safety": Outcome of a new cognitive-behavioral psychotherapy for women with posttraumatic stress disorder and substance dependence. Journal of Traumatic Stress, 11, 437-456.

National Institute of Mental Health (NIMH). (1998). Bridging science and service. Available: http://www.nimh.nih.gov/research/bridge.html.

Palacios, W.R., Urmann, C.F., Newel, R., \& Hamilton, N. (1999). Developing a sociological framework for dually diagnosed women. Journal of Substance Abuse Treatment, 17, 91-102. 


\section{A WOMAN'S DUAL DIAGNOSIS COMMUNITY MENTAL HEALTH PROGRAM}

Powis, B., Griffiths, P., Gossop, M., \& Strang J. (1996). The differences between male and female drug users: Community samples of heroin and cocaine users compared. Substance Use and Misuse, 31, 529-543.

Ridgely, M.S., Goldman, H.H., \& Talbott, J.A. (1987). Chronic mentally ill young adults with substance abuse problems: A review of the literature and creation of a research agenda. Baltimore, MD: Mental Health Policy Studies Center, University of Maryland.

Ridgely, M.S., Goldman, H.H., \& Willenbring, M. (1990). Barriers to the care of persons with dual diagnoses. Schizophrenia Bulletin, 16, 123-132.

Ridgely, M.S., Osher, F.C., Goldman, H.H., \& Talbott, J.A. (1987). Executive summary. Chronic mentally ill young adults with substance abuse problems: A review of research, treatment and training issues. Baltimore, MD: Mental Health Policy Studies Center, University of Maryland School of Medicine.

Roberts, L.J., Shaner, A., \& Eckman, T.A. (1999). Overcoming addictions: Skills training for people with schizophrenia. New York: Norton.

Schmidt, C., Klee, L., \& Ames, G. (1990). Review and analysis of literature on indicators of women's drinking problems. British Journal of Addiction, 85, 179-192.

Schober, R., \& Annis, H.M. (1996). Barriers to help-seeking for change in drinking: A gender-focused review of the literature. Addictive Behaviors, 21, 81-92.

Schoenwald, S.K., \& Hoagwood, K. (2001). Effectiveness, transportability, and dissemination of interventions: What matters when? Psychiatric Services, 52, 1190-1197.

Springer, T., Lohr, N.E., Buchtel, H.A., \& Silk, K.R. (1996). A preliminary report of shortterm cognitive-behavioral group therapy for inpatients with personality disorders. Journal of Psychotherapy Practice and Research, 5, 57-71.

Substance Abuse and Mental Health Services Administration. (1993). National Drug and Alcoholism Treatment Unit Survey (NDATUS): 1991 main findings report (DHHS Publication No. SMA 93-2007). Washington DC: U.S. Government Printing Office.

Thom, B. (1984). A process approach to women's use of alcohol services. British Journal of Addiction, 79, 377-382.

U.S. Public Health Service. (1999). Mental Health: A Report of the Surgeon General. Available: http://www.surgeongeneral.gov/library/mentalhealth/home.html.

Walitzer, K.S., \& Connors, G.J. (1997). Gender and treatment of alcohol-related problems. In R.W. Wilsnack \& S.C. Wilsnack (Eds.), Gender and alcohol (pp. 445-461). New Brunswick, NJ: Alcohol Research Documentation.

Watkins, K.E., Shaner, A., \& Sullivan, G. (1999). Addictions services: The role of gender in engaging the dually diagnosed in treatment. Community Mental Health Journal, 35, 115126.

Wells, K. B. (1999). Treatment research at the crossroads: The scientific interface of clinical trials and effectiveness research. American Journal of Psychiatry, 156, 5-10. 